\title{
Patient-Specific Patellofemoral Arthroplasty
}

\author{
Domenick J. Sisto ${ }^{1}$, Ronald P. Grelsamer ${ }^{2}$ and Vineet K. Sarin ${ }^{3}$ \\ ${ }^{1}$ Los Angeles Orthopaedic Institute, Sherman Oaks, California \\ ${ }^{2}$ Mount Sinai Medical Center, New York, New York \\ ${ }^{3}$ Kinamed Incorporated, Camarillo, California \\ USA
}

\section{Introduction}

In this chapter we review the topic of patellofemoral arthroplasty from a historical, technical, and clinical perspective. Emphasis is placed on the design rationale, surgical technique, and clinical results of so-called "patient-matched" or "patient-specific" patellofemoral arthroplasty in which the trochlear implant is matched to the anatomy of the individual patient through the use of pre-operative computerized imaging scans (Fig 1).

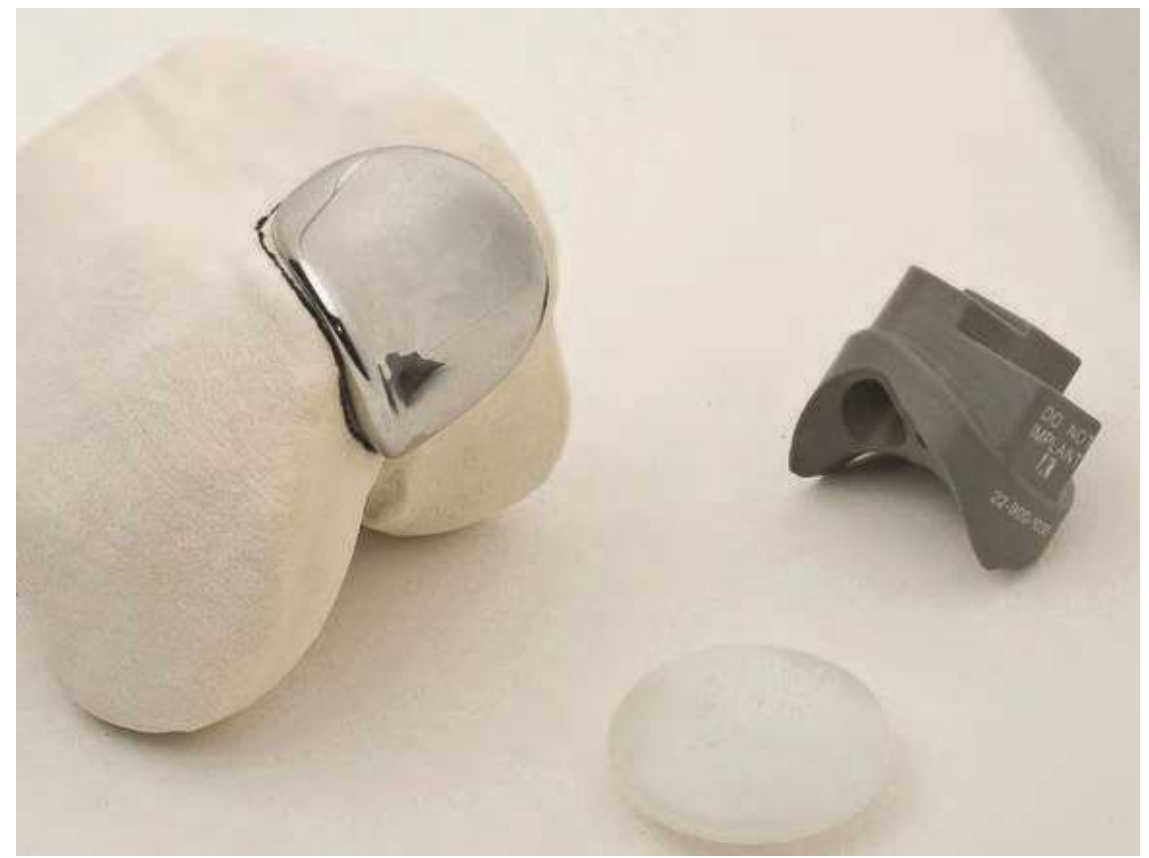

Fig. 1. Patient-specific patellofemoral implant mounted on patient-specific physical bone model, alongside a companion patient-specific drill guide \& marking template and allpolyethylene patella button. Collectively these items constitute the patient-specific patellofemoral arthroplasty system described in this chapter. 
The implants are inlayed into the articular cartilage without any intra-operative femoral bone resection. Clinical results involving patient-matched patellofemoral arthroplasty are presented with an average follow-up of 11 years. Case studies reviewing our collective experience with patient-matched trochlear implants in the setting of femoral trochlear dysplasia are also presented.

\section{Historical perspective}

The origins of patellofemoral arthroplasty (PFA or PFR) can be traced to 1955 with the introduction of the McKeever prosthesis (McKeever, 1955). This prosthesis consisted of a Vitallium $^{\circledR}$ shell used to resurface only the patella. The procedure was eventually abandoned because of concerns regarding trochlear wear (Leadbetter et al, 2006). Blazina et al (1979) reported on the use of a patellofemoral prosthesis. In the decades that followed, a number of different patellofemoral prostheses were developed and studied (Lonner, 2004; Leadbetter et al, 2005; Lonner, 2007; Sisto \& Sarin, 2008; Gupta et al, 2010). The clinical results with these designs have been highly variable, which has led to skepticism about the success of the procedure. A consensus view has emerged that appropriate patient selection and prosthesis design are the two most critical elements for achieving successful outcomes after patellofemoral arthroplasty (Arnbjornsson and Ryd, 1998; Kooijman et al, 2003; Lonner, 2004; Ackroyd et al, 2007; Lonner, 2007; Gupta et al, 2010).

\section{Indications and contraindications}

Previous authors (Grelsamer, 2006; Leadbetter et al, 2006; Lonner, 2007) have discussed in detail the indications and contraindications for patellofemoral arthroplasty. To summarize, patellofemoral arthroplasty is indicated for isolated patellofemoral degenerative arthritis of the knee, according to the following criteria:

- Degenerative or posttraumatic osteoarthritis limited to the patellofemoral joint, so that medial and lateral Ahlback scores (Ahlback, 1968) are less than or equal to 1 point;

- Severe symptoms affecting daily activity referable to patellofemoral joint degeneration unresponsive to lengthy non-operative treatment and conservative procedures;

- Patellofemoral malalignment/dysplasia induced degeneration with or without instability.

Contraindications include but are not limited to the following criteria:

- The lack of non-operative care;

- Pain referred from outside the patellofemoral compartment or even outside the knee;

- Medial and lateral tibiofemoral Ahlback scores (Ahlback, 1968) greater than 1 point;

- Systemic inflammatory arthropathy;

- Patellofemoral instability or malalignment that is uncorrectable at the time of arthroplasty.

\section{Technical considerations for a patient-specific approach}

\subsection{Motivation}

The shape and alignment of the human patellar trochlear groove is highly variable (Feinstein et al, 1996). Such variability presents a challenge for so-called "off-the-shelf" patellofemoral prostheses that feature a fixed geometry and a finite number of sizes. For 
patellofemoral compartments that deviate from an off-the-shelf implant's design paradigm, there exists an inherent tradeoff between fit and alignment that must be addressed intraoperatively. Many reported off-the-shelf implant failures are thought to be due to design deficiencies related to fit and alignment within the patellofemoral compartment (Lonner, 2004; Lonner, 2007; Gupta et al, 2010). The patient-specific approach to patellofemoral arthroplasty described in this chapter was conceived and developed in light of these challenges (Fig 2).

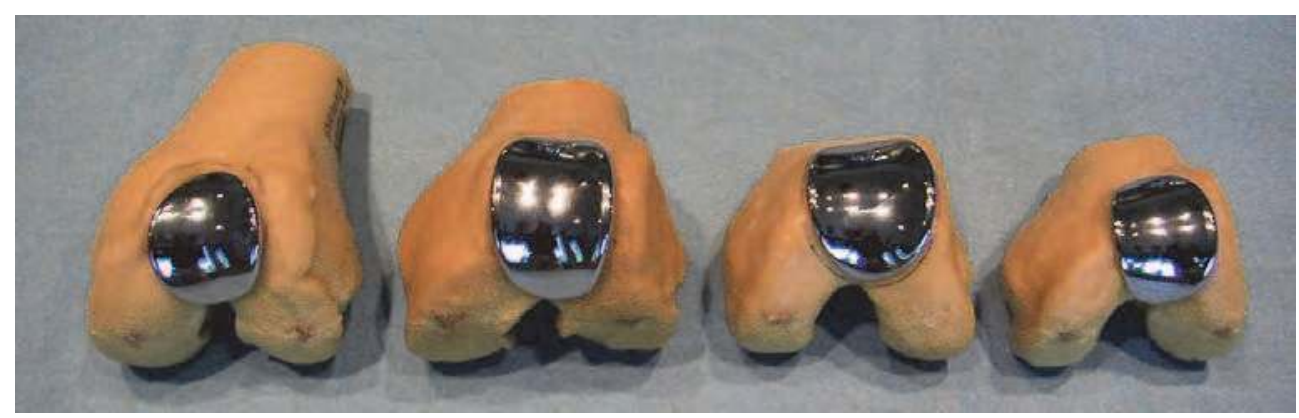

Fig. 2. Physical distal femur models from four patients treated with patient-specific patellofemoral arthroplasty (cartilage not shown). Note the substantial variation in trochlear groove geometry across this group, consistent with previously published findings. The patient-specific approach provides for a precise fit without bone resection or sculpting.

\subsection{Design rationale}

The design goal of patient-specific patellofemoral arthroplasty is to restore the mechanics of the patellofemoral compartment and maintain the native mechanics of the tibiofemoral compartments (Sisto \& Sarin, 2006; Sisto \& Sarin, 2008). Progression of arthritic disease into the medial and lateral knee compartments often contributes to the need for patellofemoral arthroplasty revision (Grelsamer, 2006). Poorly fitting off-the-shelf prostheses can detrimentally affect the mechanics of the knee joint (including the medial and lateral compartments), leading to disease progression into these compartments. Further, installing off-the-shelf prostheses can be a time-consuming process; and poorly fitting prostheses may require significant cement support. Patient-specific patellofemoral arthroplasty effectively addresses the design deficiencies and difficulties in surgical technique associated with offthe-shelf patellofemoral prostheses.

The patient-specific patellofemoral arthroplasty prosthesis described in this chapter is designed to custom-fit the bony anatomy; its bony contact surface is designed to conform to the bony anatomy of the patient's femoral trochlea using computed tomographic (CT) modeling (Fig 3). This approach allows for a precise fit of the implant to the trochlea without resection of subchondral femoral bone, as is necessary for so-called "onlay" off-the-shelf prostheses. Only removal of the overlying cartilage is necessary to obtain a precise fit with a patient-specific prosthesis. The trochlear prosthesis is designed to approximate normal patellofemoral kinematics by re-establishing a trochlear groove. 


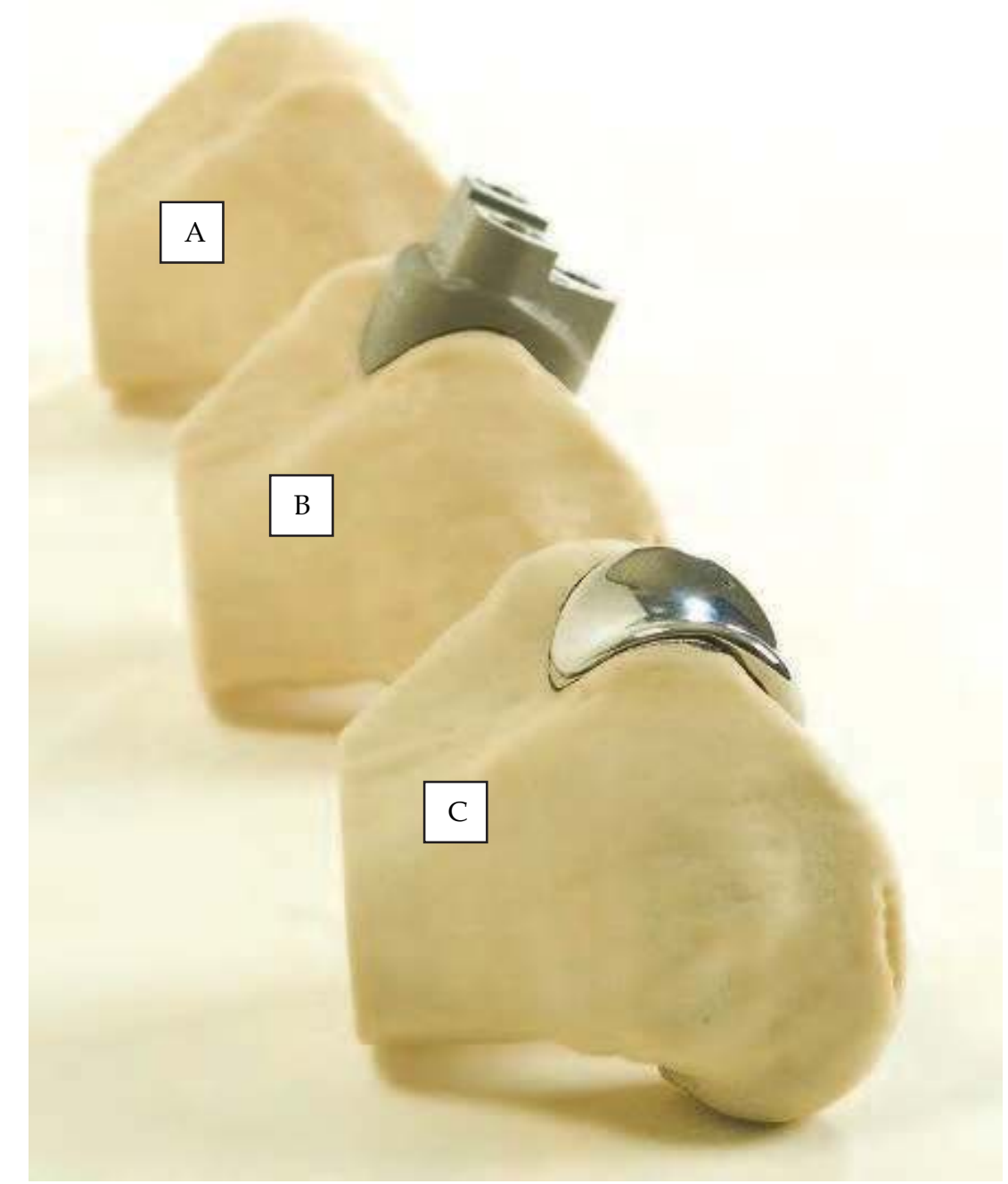

Fig. 3. Native patient-specific physical bone model (A), patient-specific bone model with companion patient-specific drill guide \& marking template (B), and patient-specific bone model with companion patient-specific trochlear implant $(\mathrm{C})$. Note the precise fit between patient-specific components and native unresected trochlear bone.

The distal margin of the patient-specific trochlear prosthesis is designed to rest 3 to $5 \mathrm{~mm}$ from the apex of the intercondylar notch. The prosthesis has a thickened lateral border to compensate for bone loss along the lateral edge of the trochlear groove and to provide congruency and tracking stability with the matching patellar implant. The thickened implant border does not anteriorize ("stuff") the patella relative to its pre-operative state because the anterior position of a given patella is defined by the thickness of the femoral implant's trochlear groove. The patient-specific femoral prosthesis may seem thick on lateral 
radiographs, but only because the radiograph is a 2-dimensional projection of a saddleshaped structure.

The articular side of the patellofemoral implant has a radius of curvature matched to the curvature of a standard dome patellar implant. It is designed to constrain the patellar implant medially and laterally as it tracks along the trochlear groove. This design is, therefore, able to compensate for a deficient or dysplastic trochlear groove, which is often present in patellofemoral surgery candidates.

The bony-contact surface and the articulating surface of the patient-specific trochlear implant are "decoupled." The bony-contact surface is customized to fit the bony anatomy, while the articulating surface is designed to mate with a patella button prosthesis and provide medial-lateral constraint to the patella. The medial and lateral borders of the articular surface are thickened by a few millimeters to provide stability and congruency for the patella button.

The design rationale of patient-specific patellofemoral arthroplasty therefore eliminates the trade-off between fit and alignment that is inherent to off-the-shelf, particularly inlay, patellofemoral implants.

\subsection{Stuffing}

Overstuffing of the patellofemoral compartment has been cited (Lonner, 2007) as a concern over the use of patient-specific patellofemoral arthroplasty. Although this may be a theoretical concern, it has not been borne out by the clinical results. Moreover, the concept of patellofemoral overstuffing has been challenged. Merchant and colleagues (2008) state the following:

The concept of overstuffing the patellofemoral joint has been simply and uncritically transferred from the femorotibial joint with no confirmatory studies. Because the capsule and inelastic ligaments secure the femorotibial joint, it is extremely important to balance these ligaments carefully during TKA and avoid a tibial insert that is too large. This will certainly overstuff this joint and lead to a poor result with decreased range of motion. The patellofemoral joint is a totally different articulation. Although the patellar ligament is inelastic, the quadriceps muscles are elastic and stretchable. This explains why the investigation by Bengs and Scott (2006) failed to support the claim of overstuffing by Conley et al (2007). More recently, Pierson et al (2007) reviewed 830 primary TKAs to determine the effects of so-called overstuffing the patellofemoral joint. Their findings did "not support the widely held belief that stuffing of the patellofemoral joint results in adverse outcomes after total knee arthroplasty."

The trochlear prosthesis is designed to restore the anterior position of the non-degenerated patella. The thickness of normal articular cartilage is approximately 5 to $7 \mathrm{~mm}$ on the patella and 2 to $3 \mathrm{~mm}$ in the trochlea, yielding a combined total cartilage thickness of 7 to $10 \mathrm{~mm}$ (Grelsamer, 2000). The trochlear prosthesis typically is 2 to $5 \mathrm{~mm}$ thick along its center arc, the tracking arc of the patella. This thickness is a function of native trochlear groove depth (i.e., thinner implants are created for shallower grooves). The thinner implants are designed specifically to avoid overstuffing the more dysplastic trochleas. Coupled with an anatomic restoration of the patella, the extensor lever arm is intended to be unchanged or improved from the pre-operative condition (see Fig 6, described later in this chapter). If concerns about overstuffing still persist, accommodations can be made by resecting more bone on the patellar side or by selecting a thinner patellar implant. 


\section{Peri-operative technique}

The peri-operative technique for patient-specific patellofemoral arthroplasty has been previously described (Sisto \& Sarin, 2007; Sisto et al, 2010; Lombardi, 2011) and consists of pre-operative planning, intra-operative technique, and post-operative management.

\subsection{Pre-operative planning}

A CT scan of the patient's knee is obtained using the following settings as specified by the manufacturer of the prosthesis (Kinamed Incorporated, Camarillo, California, USA):

- Voltage: 120 to $140 \mathrm{kV}$;

- Amperage: 200 to $300 \mathrm{~mA}$;

- Scan Region: $5 \mathrm{~mm}$ distal to the femoral condyles to $10 \mathrm{~mm}$ proximal to the patella.

Computer modeling is then used to create a 3-dimensional physical model of the patient's distal femoral bone, which is sent to the surgeon. The manufacturer identifies the perimeter of coverage of the trochlear implant on this model. If deemed necessary based on the presence of significant osteophytes or bony defects in or near the native trochlea, the surgeon may physically remove osteophytes from the model and communicate these changes by returning the model to the implant manufacturer. The final design for the trochlear implant is then created after surgeon approval.

If changes are made during the design review, during surgery the surgeon will modify the real trochlear groove in the same manner as was done on the physical model. For this reason, it is imperative that the physical model be available for visual examination in the operating theatre.

It must be noted that patellofemoral arthroplasty is not a substitute for a patellar realignment procedure. Patella tracking must be evaluated for instability and soft tissue imbalance (Lonner, 2004; Grelsamer, 2000). Malalignment of the patella is determined through physical examination and standard radiographic evaluation. Assessment of patellar tracking is important in pre-operative planning, as patellar instability is the most often reported cause of dysfunction after patellofemoral arthroplasty. Tightness of the lateral retinaculum is often associated with lateralization and patellar tilt, which may be determined upon physical examination. Examination of medial structures for deficiency should also be carried out, as well as assessment of the tibial tuberosity ( $Q$ angle). Axial and lateral radiographs are often sufficient to quantify measures of patellar malalignment, including patella alta or baja, medial-lateral displacement and patellar tilt. Treatments are generally customized to each patient, although it remains to be determined if there are one or more standard procedures that will be optimal for most patients (Grelsamer, 2000).

\subsection{Intra-operative technique}

A standard midline incision is made to expose the patellofemoral joint, and the patella is everted or tilted $90^{\circ}$. The length of the incision is typically two-thirds the length of a standard total knee incision because tibial exposure is not necessary. The margin of cartilage to be removed is determined by placing the patient-specific drill guide onto the trochlea. Because the cartilage remnants on the trochlea will initially not permit a proper fit of the patient-specific custom drill guide, the surgeon first approximates the proper position of the drill guide (using the CT-created physical bone model as a template). The surgeon outlines the drill guide with methylene blue and by way of a ring curette removes the cartilage inside that outline. Osteophytes are removed as necessary. The patient-specific drill guide is then placed on the subchondral bone of the trochlea and moved slightly back and forth until 
it seats in its intended position as determined by the CT scan. Two headless nails are then used to secure the drill guide and the three holes are drilled. The holes are then thoroughly irrigated to remove any debris that may be present.

The trochlear prosthesis is designed to be used in conjunction with a standard off-the-shelf all-polyethylene patellar button of onlay design with a $25 \mathrm{~mm}$ radius of curvature. The residual patellar thickness is the same as with total knee arthroplasty.

During trialing, particular attention is paid to potential subluxation or catching within the limitations of a patient under anesthesia (Lonner, 2004). If realignment is necessary, balancing is carried out in the same manner as a non-prosthetic or total knee arthroplasty. To correct patellar tilt or lateral displacement of the patella, a proximal realignment procedure such as a lateral retinacular release, medial plication, vastus medialis obliquus advancement, and/or medial patellofemoral ligament repair may be carried out (Grelsamer, 2000). In the presence of a high $Q$ angle, a distal realignment procedure such as transfer of the tibial tuberosity may be carried out to correct alignment of the extensor mechanism (Grelsamer, 2000). Any realignment or soft-tissue balancing strategy should be oriented toward addressing specific identifiable pathology (Grelsamer, 2000).

Cementing is carried out in standard knee arthroplasty fashion. Particular care needs to be taken to avoid cement seepage into the notch or other compartments. The cartilage of the other compartments must be kept moist throughout the procedure to avoid deterioration. Patellofemoral tracking is again evaluated and soft tissue corrections are carried out as necessary to ensure optimal patellar tracking.

\subsection{Post-operative management}

The need for prophylaxis against deep venous thrombosis has not been shown for patellofemoral replacement surgery. Postoperative rehabilitation consists of range of motion exercises as with any knee arthroplasty. As a rule, though, progress will be much quicker than with total knee arthroplasty patients. Immediate full-weight bearing is allowed. Physical therapy to restore quadriceps strength is encouraged. Twisting activities are discouraged, but no additional specific activity modifications are recommended.

\section{Clinical results}

Previous investigators have reported on clinical results obtained with off-the-shelf and patient-specific patellofemoral arthroplasty.

\subsection{Results with off-the-shelf implants}

Published clinical results with off-the-shelf patellofemoral implants have been previously reviewed in detail (Lonner, 2007; Sisto \& Sarin, 2008; Gupta et al, 2010; Charalambous et al, 2011). These references cover twenty one studies that each involved from 14 to 306 patients who received 8 different off-the-shelf designs, with follow-up ranging from 6 months to 21 years. These reports demonstrate that clinical results with off-the-shelf patellofemoral implant designs have been highly variable.

The Australian national joint replacement registry reports that the cumulative revision rate at five and seven years for off-the-shelf patellofemoral implants used in the setting of primary osteoarthritis is $15.2 \%$ and $22.4 \%$, respectively (Australian Orthopaedic Association, 2010). 


\subsection{Results with patient-matched Implants \\ 6.2.1 Prior investigation}

In an earlier published investigation (Sisto and Sarin, 2006), 100\% survivorship with excellent or good Knee Society scores was reported at a mean duration of follow-up of 73 (range, 32 to 119) months. The study was a retrospective review of a consecutive singlesurgeon series of patient-specific patellofemoral arthroplasties performed between March 1995 and August 2002. There were 25 patellofemoral arthroplasties performed in 22 patients (three staged bilaterals), 16 of whom were female. Mean age at the time of index arthroplasty was 45 (range, 23 to 51) years.

Only patients whose medial and lateral compartments scored less than or equal to 1 point on the Ahlback scale were indicated for patellofemoral arthroplasty. The patellofemoral compartments for all knees scored at least 4 points. The mean pre-operative Knee Society functional score was 49 points, and the mean pre-operative Knee Society objective score was 52 points.

There were 18 excellent and 7 good results at 73 months of follow-up. The mean postoperative Knee Society objective score was 91 (range, 82 to 96) points, and the mean postoperative Knee Society functional score was 89 (range, 81 to 94) points. All patients exhibited good to excellent Knee Society Score status and no patient had required additional surgery or had component loosening.

\subsubsection{Eleven year follow-up}

The objective of the eleven year follow-up study was to evaluate the longer-term success of patient-specific patellofemoral arthroplasty in the original patient cohort. For assessment of

\begin{tabular}{|c|c|}
\hline Question & Answer \\
\hline Has your custom PFA been replaced? & $\begin{array}{l}\text { No: } 25 \text { out of } 25 \\
\text { Yes: } 0\end{array}$ \\
\hline $\begin{array}{l}\text { Does your PFA keep you from doing anything that you } \\
\text { would like to do? }\end{array}$ & $\begin{array}{l}\text { No: } 23 \text { out of } 25 \\
\text { Yes: } 2 \text { out of } 25\end{array}$ \\
\hline How satisfied are you with your PFA? & \begin{tabular}{|lr} 
Very Dissatisfied: & 0 out of 25 \\
Somewhat Satisfied: & 0 out of 25 \\
Very Satisfied: $\quad 25$ out of 25
\end{tabular} \\
\hline $\begin{array}{l}\text { Have you had additional surgery on this knee since your } \\
\text { PFA? }\end{array}$ & $\begin{array}{l}\text { No: } 25 \text { out of } 25 \\
\text { Yes: } 0\end{array}$ \\
\hline $\begin{array}{l}\text { How often do you take pain medication because of pain in } \\
\text { this knee? }\end{array}$ & $\begin{array}{l}\text { Never: } 25 \text { out of } 25 \\
\text { Sometimes (1-2x per week): } 0 \\
\text { Often (>1 per day): } 0 \\
\end{array}$ \\
\hline If you have pain, where is the pain coming from? & $\begin{array}{lr}\text { Inside of Knee: } & 3 \text { out of } 25 \\
\text { Kneecap area: } & 21 \text { out of } 25 \\
\text { Outside of Knee: } & 1 \text { out of } 25\end{array}$ \\
\hline Does this knee feel weak or unstable? & $\begin{array}{l}\text { No: } 25 \text { out of } 25 \\
\text { Yes: } 0\end{array}$ \\
\hline Would you undergo PFA with this custom implant again? & $\begin{array}{l}\text { No: } 0 \\
\text { Yes: } 25 \text { out of } 25\end{array}$ \\
\hline
\end{tabular}

Table 1. The original cohort included 25 patellofemoral arthroplasties (PFAs) in 22 patients. Each patient from the original cohort answered via telephone the above-listed questions, which were selected and adapted from the validated "Total Knee Function Questionnaire" (Weiss et al, 2002). All patients were successfully contacted and no knees were lost. Average time from index patellofemoral arthroplasty to completion of the questionnaire was 11.3 years (range, 7.8 to 14.9 years). 
longer-term follow-up, the validated "Total Knee Function Questionnaire" (Weiss et al, 2002) was adapted and administered via telephone to each patient from the abovementioned prior study. The questions were designed to assess the status of each patient's patellofemoral arthroplasty as well as their degree of knee function.

The questionnaire was completed for all 25 knees (Table 1). No knees from the original study were lost to follow-up. At a mean duration of 11.3 years (range, 7.8 to 14.9 years) from the index arthroplasty, all 25 patellofemoral arthroplasties were still in place and all patients reported themselves as being very satisfied. There were no reports of weakness, instability, or additional surgery. Two patients reported that despite their patellofemoral arthroplasty, they were not participating in sports activities. All patients experienced some pain, but not enough to warrant medication. All 22 patients said they would undergo the procedure again.

This 11 year follow-up study demonstrates that patient-specific patellofemoral arthroplasty is a safe and effective treatment for patients with isolated patellofemoral arthritis of the knee. These results compare favorably with those involving off-the-shelf patellofemoral arthroplasties that have been reported on over the past 30 years (Leadbetter et al, 2005; Leadbetter et al, 2006; Lonner, 2007; Sisto and Sarin, 2008; Gupta et al, 2010).

\subsection{Complications}

Progression of arthritis into the tibiofemoral compartment is a recognized complication of patellofemoral replacement; when symptomatic, this scenario leads to conversion to a total knee arthroplasty. Progression is more likely to develop when the disease patellofemoral arthritis does not have a clear origin, such as idiopathic arthritis (Grelsamer, 2006). Despite attempts to balance the extensor mechanism, patellar maltracking after patellofemoral arthroplasty can occur, especially when the patient pre-operatively demonstrates high level malalignment and/or dysplasia.

\section{Case studies}

Our (DJS and RPG) collective experience with patient-specific patellofemoral arthroplasty dates back to 1995 and consists of 91 cases in 79 patients through May 2011. Patients in our cohort generally fall into one of two categories: those having a "normal" femoral trochlear sulcus angle, with or without patellar tilt; and those having a femoral sulcus angle greater than $145^{\circ}$, i.e. a shallow or even convex trochlea - dysplastic trochleas will exhibit a crossing sign on a true lateral radiograph (Bollier and Fulkerson, 2011). The following case studies serve as illustrative examples.

\subsection{Normal trochlear anatomy}

Patient J.O. is a 49 year old male who initially presented with severe anterior knee pain 14 years ago after sustaining a twisting injury to his knee that was treated with arthroscopic surgery followed by a soft tissue realignment procedure two years later. During this time, he developed progressive and disabling anterior knee pain. He could not walk up or down stairs without assistance and could not kneel, squat or climb without severe pain.

Physical examination revealed severe anterior knee tenderness with severe crepitus and grinding in the retro-patellar space. He had no ligament instability and no medial or lateral joint line tenderness. All provocative tests for meniscal and ligamentous injury were 
negative. The radiographs revealed severe patellofemoral arthritis and no medial or lateral joint line abnormalities (Fig 4).
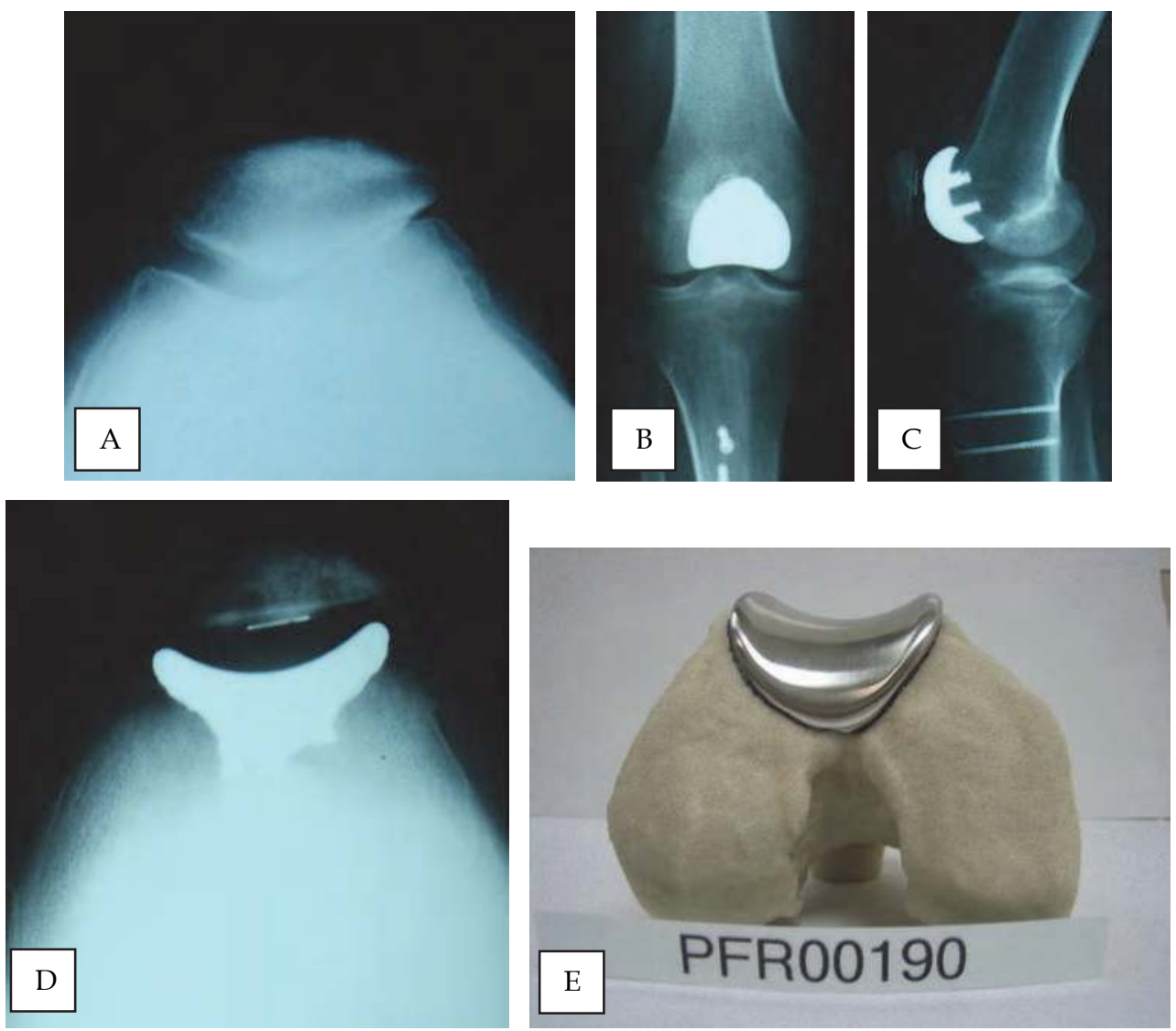

Fig. 4. A 49 year old male with isolated end-stage patellofemoral arthritis, without evidence of trochlear dysplasia as seen in pre-operative Merchant view (A), treated with a patientmatched patellofemoral prosthesis and all-polyethylene patella button. Post-operative anterior-posterior (B), lateral (C), and Merchant (D) views demonstrate proper orientation of patellofemoral prosthesis. Placement, fit, and alignment of the patient-specific trochlear implant was confirmed by the manufacturer using the patient-specific CT bone model prior to final polishing (E). See section 7.1 for additional case details.

The patient was initially treated with medications, heat, physical therapy and hyalgan injections without relief, and he remained symptomatic and disabled. In October 2009, he underwent a patient-matched custom patellofemoral arthroplasty of the right knee (Fig 4). Post-operatively, he has done remarkably well and has returned to his previous employment at the Los Angeles County Sheriff's Department. He currently has no pain and does not require any medications. He can ambulate up and down stairs without assistance and can kneel, squat and climb without pain. 


\subsection{Trochlear dysplasia}

Patient D.B. is a 56 year old woman with anterior knee pain since her teenage years. Nonoperative treatments had included activity modification, prescription and over-the-counter
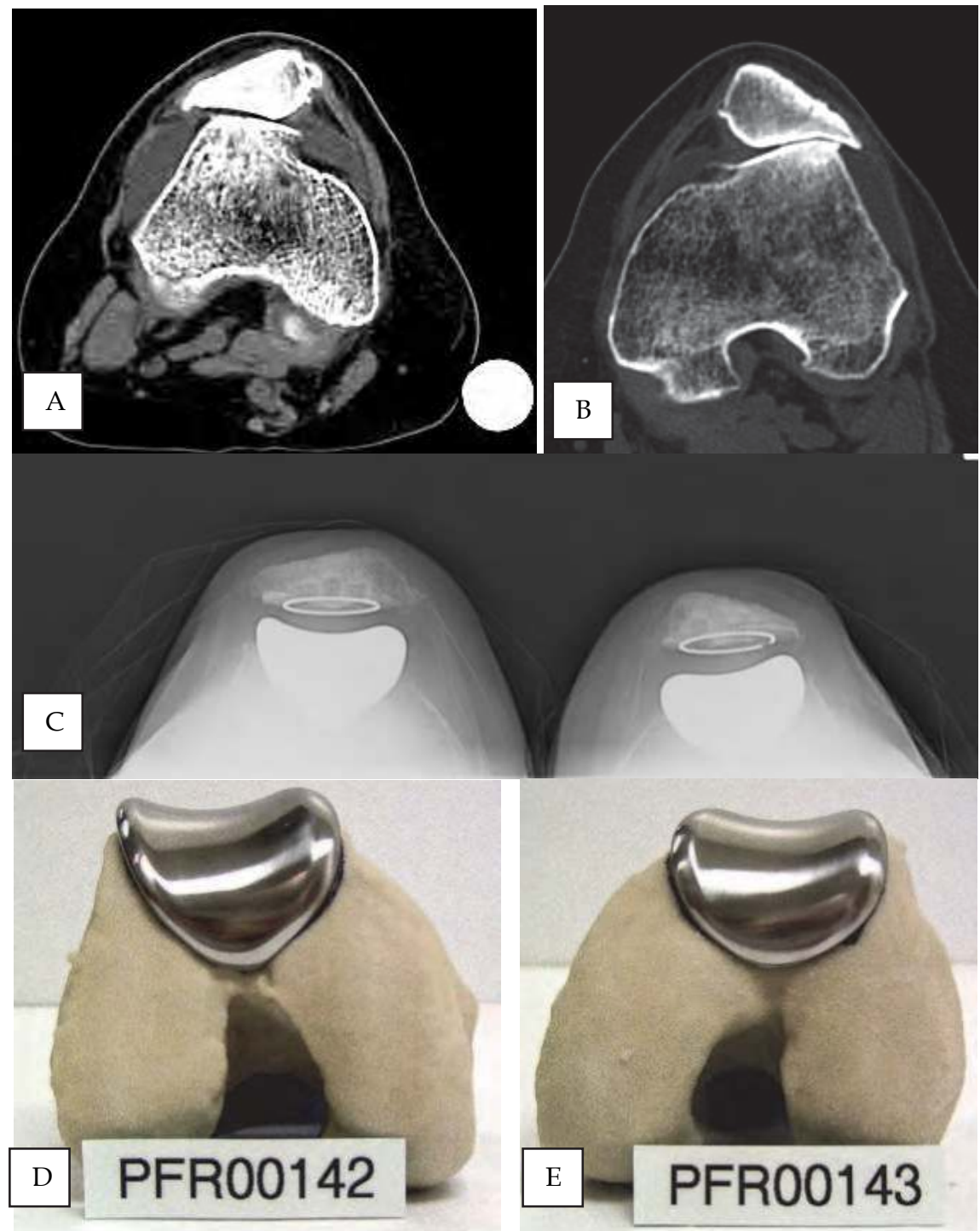

Fig. 5. A 56 year old female with bilateral isolated end-stage patellofemoral arthritis, with bilateral trochlear dysplasia (A, B), treated with patient-matched patellofemoral prostheses. Post-operative Merchant views (C) demonstrate proper orientation of patellofemoral implant components. Placement, fit, and alignment of both patient-specific trochlear implants were confirmed by the manufacturer using the patient-specific CT bone models prior to final polishing (D, E). See section 7.2 for additional case details. 
pain medications, steroid and visco-supplementation injections, nutritional supplements, and physical therapy. Serum laboratory studies had not been suggestive of inflammatory arthritis.

Imaging studies demonstrated severe patellofemoral dysplasia and an absence of arthritis outside the patellofemoral compartment (Fig 5). She had undergone arthroscopies of both knees. She underwent patient-matched custom patellofemoral arthroplasty in September 2008 for her right knee and in December 2008 for her left knee.

Despite the chronically subluxed position of her patellae pre-operatively, an extensive intraoperative lateral release and medial plication have been sufficient to maintain her patellae centered within the patient-matched custom trochlear implant (Fig 5). She flexes easily to at least 120 degrees. The patient considers the procedure a success.
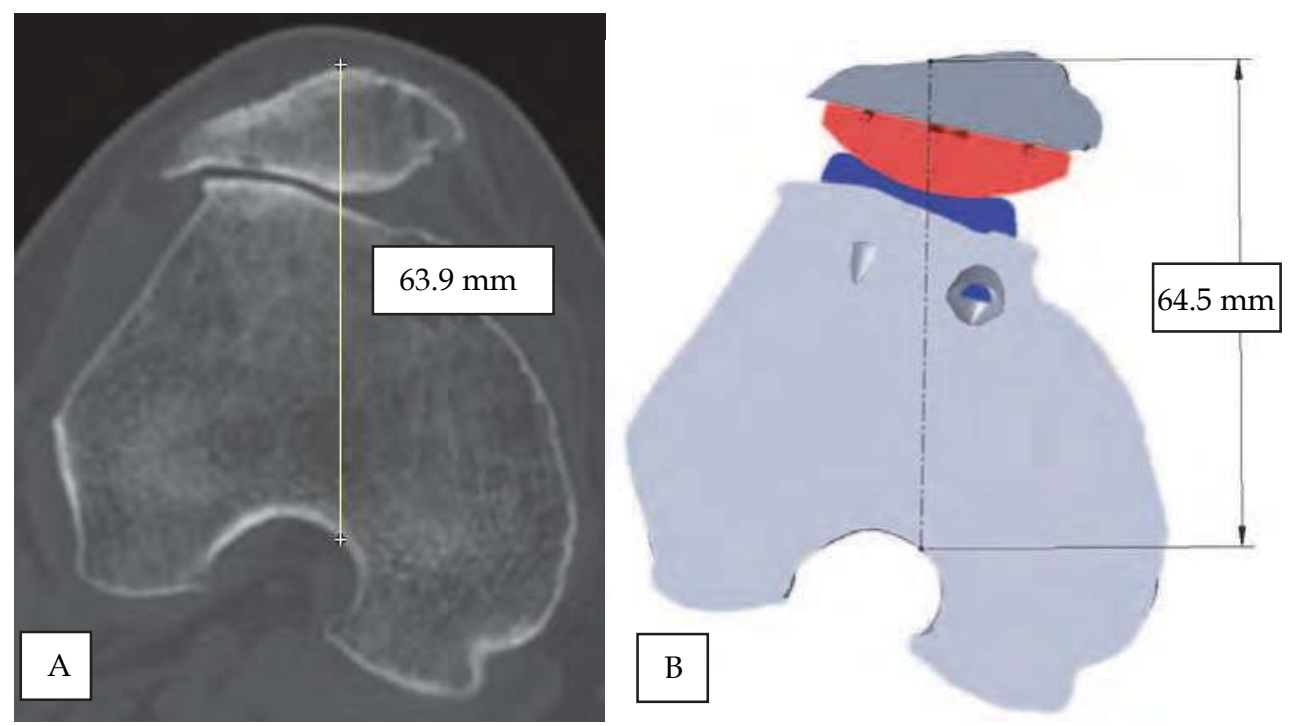

Fig. 6. Comparison of (A) pre-operative and (B) post-operative anterior-posterior patellar offset for the right knee described in Figure 5. Post-operative measurements were based on the known geometry of the patient-matched patellofemoral implant and the all-polyethylene patella selected at the time of surgery. In the presence of pronounced trochlear dysplasia (Figures 5A and 6A), treatment with a patient-specific patellofemoral arthroplasty prosthesis resulted in an insignificant net change in patellar offset $(0.6 \mathrm{~mm})$.

\section{Conclusion}

In this chapter we have reviewed the topic of patellofemoral arthroplasty from historical, technical, and clinical perspectives. The design rationale, peri-operative techniques, and 11 year clinical results of patient-matched patellofemoral arthroplasty have been reviewed and discussed. Experience with patient-matched trochlear implants in the setting of normal and dysplastic femoral trochleas have also been presented.

Patient-specific patellofemoral arthroplasty is a safe and effective treatment for patients with isolated patellofemoral arthritis. The results compare favorably with off-the-shelf 
patellofemoral arthroplasties that have been reported on over the past thirty years (Leadbetter et al, 2005; Leadbetter et al, 2006; Lonner, 2007; Sisto and Sarin, 2008; Gupta et al, 2010) and can be carried out more efficiently.

We believe the key elements that contribute to the success of patient-specific patellofemoral arthroplasty are as follows: (a) a strict inclusion criteria based on pre-operative radiographic evaluation; (b) a meticulous attention to soft-tissue balance and patellofemoral tracking at the time of arthroplasty; and (c) a patient-specific design and manufacturing methodology that ensures accurate and precise anatomic fit while simultaneously providing proper patellofemoral alignment and medial-lateral constraint.

\section{References}

Ackroyd CE, Newman JH, Evans R, Eldridge JD, Joslin CC (2007) The Avon patellofemoral arthroplasty: five-year survivorship and functional results. . J Bone Joint Surg, Vol. 89-B, pp. 310-5.

Ahlback S (1968) Osteoarthritis of the Knee. A Radiologic Investigation. Acta Radiol Diagn (Stockh), Vol. 277, pp. 7-72.

Arnebjornsson AH and Ryd L (1998) The use of isolated patellar prostheses in Sweden 19771986. Int Orthop, Vol. 22, No. 3, pp. 141-4.

National Joint Replacement Registry of Australia, Annual Report (2010).

Bengs BC and Scott RD (2006) The effect of patellar thickness on intraoperative knee flexion and patellar tracking in total knee arthroplasty. J Arthroplasty, Vol. 21, pp. 650-655.

Blazina ME, Fox JM, Del Pizzo W (1979) Patellofemoral replacement. Clin Orthop Rel Res, Vol. 144, pp. 98-102.

Bollier M and Fulkerson JP (2011) The role of trochlear dysplasia in patellofemoral instability. J Am Acad Orthop Surg, Vol. 19, No. 1, pp. 8-16.

Charalambous CP, Abiddin Z, Mills SP, Rogers S, Sutton P, Parkinson R (2011) The low contact stress patellofemoral replacement: High early failure rate. J Bone Joint Surg, Vol. 93-B, pp. 484-9.

Conley S, Rosenberg A, Crowninshield R (2007) The female knee: anatomic variations. J Am Acad Orthop Surg, Vol. 15 (suppl 1), pp. S31-S36.

Feinstein WK, Noble PC, Kamaric E, Tullos HS (1996) Anatomic alignment of the patellar groove. Clin Orthop Rel Res, Vol. 331, pp. 64-73.

Fulkerson JP (2004) Disorders of the Patellofemoral Joint. $4^{\text {th }}$ Edition. Philadelphia, PA. Lippincott Williams \& Wilkins.

Grelsamer RP (2000) Current concepts review. Patellar malalignment. J Bone Joint Surg, Vol. 82-A, pp. 1639-1650.

Grelsamer RP (2006) Current concepts review. Patellofemoral Arthritis. J Bone Joint Surg, Vol. 88-A, pp. 1849-1860.

Gupta RR, Zywiel MG, Leadbetter WB, Bonutti P, Mont MA (2010) Scientific Evidence for the Use of Modern Patellofemoral Arthroplasty. Expert Rev Med Devices, Vol. 7, No. 1, pp. 51-66.

Kooijman HJ, Driessen AP, van Horn JR (2003) Long-term results of patellofemoral arthroplasty. A report of 56 arthroplasties with 17 years of follow-up. . J Bone Joint Surg, Vol. 85-B, pp. 836-40

Leadbetter WB, Ragland PS, Mont MA (2005) The appropriate use of patellofemoral arthroplasty. Clin Orthop Rel Res, Vol. 436, pp. 91-99. 
Leadbetter WB, Seyler TM, Ragland PS (2006) Indications, Contraindications, and Pitfalls of Patellofemoral Arthroplasty. J Bone Jt Surg, Vol. 88-A(Suppl 4), pp. 122-137.

Lombardi AV (2011) Patellofemoral Arthroplasty: Custom Inlay Technique Offers a Patient Specific Approach. Annual Meeting of the American Academy of Orthopaedic Surgeons, pp. 142-144, San Diego, California, USA.

Lonner JH (2004) Patellofemoral Arthroplasty. Pros, Cons, and Design Considerations. Clin Orthop Rel Res, Vol. 428, pp. 158-165.

Lonner JH (2007) Patellofemoral Arthroplasty. J Am Acad Orthop Surg, Vol. 15, No. 8, pp. 495-506.

McKeever DC (1955) Patellar prosthesis. J Bone Joint Surg, Vol. 37-A, pp. 1074-1084.

Merchant AC, Arendt EA, Dye SF, Fredericson N, Grelsamer RP, Leadbetter WB, Post WR, Teitge RA (2008) The Female Knee. Anatomic Variations and the Female-Specific Total Knee Design. Clin Orthop Rel Research, Vol. 466, pp. 3059-3065.

Pierson JL, Ritter MA, Keating EM, Faris PM, Meding JB, Berend ME, Davis KE (2007) The effect of stuffing the patellofemoral compartment on the outcome of total knee arthroplasty. J Bone Joint Surg, Vol. 89-A, pp. 2195-2203.

Sisto DJ and Sarin VK (2006) Custom Patellofemoral Arthroplasty of the Knee. J Bone Jt Surg, Vol. 88-A, No. 7, pp. 1475-1480.

Sisto DJ and Sarin VK (2007) Custom Patellofemoral Arthroplasty of the Knee. Surgical Technique. J Bone Jt Surg, Vol. 89-A(Suppl 2), pp. 214-225.

Sisto DJ and Sarin VK (2008) Patellofemoral Arthroplasty with a Customized Trochlear Prosthesis. Orthopedic Clinics of North America, Vol. 39, No. 3, pp. 355-62.

Sisto DJ, Henry J, Sisto M, Sarin VK (2010) Patient-Specific Patellofemoral Arthroplasty. Techniques in Knee Surgery, Vol. 9, pp. 188-192.

Sisto DJ and Sarin VK (2011) Custom Patellofemoral Arthroplasty of the Knee: An Eleven Year Follow-Up. Transactions of the Orthopaedic Research Society, p. 1239, Long Beach, California, USA.

Weiss JM, Noble PC, Conditt MA, Kohl HW, Roberts S, Cook KF, Gordon MJ, Mathis KB (2002) What functional activities are important to patients with knee replacements? Clin Orthop Rel Res. Vol. 404. pp. 172-188. 


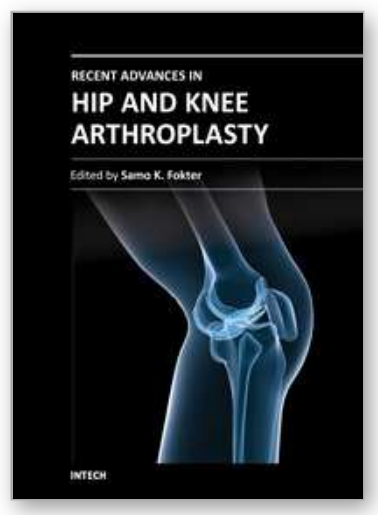

\author{
Recent Advances in Hip and Knee Arthroplasty \\ Edited by Dr. Samo Fokter
}

ISBN 978-953-307-841-0

Hard cover, 452 pages

Publisher InTech

Published online 27, January, 2012

Published in print edition January, 2012

The purpose of this book is to offer an exhaustive overview of the recent insights into the state-of-the-art in most performed arthroplasties of large joints of lower extremities. The treatment options in degenerative joint disease have evolved very quickly. Many surgical procedures are quite different today than they were only five years ago. In an effort to be comprehensive, this book addresses hip arthroplasty with special emphasis on evolving minimally invasive surgical techniques. Some challenging topics in hip arthroplasty are covered in an additional section. Particular attention is given to different designs of knee endoprostheses and soft tissue balance. Special situations in knee arthroplasty are covered in a special section. Recent advances in computer technology created the possibility for the routine use of navigation in knee arthroplasty and this remarkable success is covered in depth as well. Each chapter includes current philosophies, techniques, and an extensive review of the literature.

\title{
How to reference
}

In order to correctly reference this scholarly work, feel free to copy and paste the following:

Domenick J. Sisto, Ronald P. Grelsamer and Vineet K. Sarin (2012). Patient-Specific Patellofemoral Arthroplasty, Recent Advances in Hip and Knee Arthroplasty, Dr. Samo Fokter (Ed.), ISBN: 978-953-307-8410, InTech, Available from: http://www.intechopen.com/books/recent-advances-in-hip-and-kneearthroplasty/patient-specific-patellofemoral-arthroplasty

\section{INTECH}

open science | open minds

\section{InTech Europe}

University Campus STeP Ri

Slavka Krautzeka 83/A

51000 Rijeka, Croatia

Phone: +385 (51) 770447

Fax: +385 (51) 686166

www.intechopen.com

\section{InTech China}

Unit 405, Office Block, Hotel Equatorial Shanghai

No.65, Yan An Road (West), Shanghai, 200040, China

中国上海市延安西路65号上海国际贵都大饭店办公楼 405 单元

Phone: +86-21-62489820

Fax: $+86-21-62489821$ 
(C) 2012 The Author(s). Licensee IntechOpen. This is an open access article distributed under the terms of the Creative Commons Attribution 3.0 License, which permits unrestricted use, distribution, and reproduction in any medium, provided the original work is properly cited. 